\title{
PREreview for Reflexão de práticas e vivências entre a Universidade e Escola a partir do Programa de Residência Pedagógica
}

\author{
Michel Kobelinski ${ }^{1}$ and Ana Carolina de D. Bueno Krawczyk ${ }^{1}$ \\ ${ }^{1}$ Ensino \& Pesquisa
}

May 5, 2020

Resumo: este é um Grupo de Revisores de pré-impressão da Revista Ensino \& Pesquisa, o qual avaliou o artigo Reflexão de práticas e vivências entre a Universidade e Escola a partir do Programa de Residência Pedagógica, de Josiane Ap. Gomes Figueiredo, Roberta Ravaglio Gagno . A Préimpressão foi originalmente publicada no referido repositório em 17 de dezembro de 2019. (DOI: https: //doi.org/10.22541/au.157660100.07880567).

Estimadas autoras, agradecemos o envio do seu artigo para o nosso repositório Preprint. Depois de analisarmos a submissáo, elaboramos o parecer que segue logo abaixo.

O artigo de Josiane Aparecida Gomes Figueiredo e Roberta Ravaglio Gagno, que tem como objetivo refletir as ações de implementação de projeto no Programa de Residência Pedagógica (BRASIL, 2018), é uma contribuição significativa sobre a formação/práticas docentes desenvolvidas a partir do curso de Ciências Biológicas da Universidade Estadual do Paraná (campus de Paranaguá), assim como sobre as demandas do ensino em algumas escolas do litoral paranaense. As discussões sobre a educação de qualidade na educação superior e no ensino básico são fundamentais para refletirmos problemas estruturais de décadas, especialmente quando relacionadas ao "ensino e vida, conhecimento e ética, reflexão e ação". Para isto, as autoras consideram que uma visão ampla e relacional deve priorizar através de ações colaborativas, as injunções sociais, conteúdos, práticas pedagógicas inovadoras, projetos e ações que contemplem uma formação humanizada, engajada e inclusiva. Porém, no tocante às retóricas da eficiência e da qualidade da educação pode-se levar em conta tanto os resultados quanto o próprio processo de ensino-aprendizagem, almejando o (polêmico) conceito de "capital social". Este, por sua vez, pode ter dois enfoques, cuja aplicação abrange o desempenho escolar e o contexto social. Um com orientação política em Bourdieu, que valoriza os vínculos entre cultura, redes sociais e poder (Bourdieu, 1979). Outro, de orientação econômica, elaborado por Coleman, que versa sobre a intangibilidade em espaços relacionais estabelecidos por e entre pessoas (Coleman, 1988). No entanto, ambos comungam a ideia de que as relações sociais são vitais a todos ao se basear no princípio da reciprocidade, da confiança e da cooperação, abrangendo tanto a ação social quanto o ator social. Para Gomes Figueiredo \& Gagno a universidade e a escola são espaços híbridos de formação teórica e prática, que beneficiam universitários e comunidade com um ensino de qualidade e uma formação profissional adequada. Daí resulta a importância diretiva da universidade, a troca de aprendizagens, a problematização de conteúdos e do cotidiano escolar, bem como a legitimidade de ações teórico-práticas nestes diferentes níveis, apesar dos problemas estruturais, formativos e de valorização dos professores. Sem dúvida o ensino de qualidade diz respeito a atuação da universidade como "comunidades eficazes de aprendizagem", apesar de algumas práticas pedagógicas serem estigmatizadas, sobretudo nas redes sociais, onde extremismos político-partidários compõem retóricas de ocasião. É conveniente frisar aqui alguns temas tocados pelas autoras em relação ao ensino-aprendizagem, os quais podem, de alguma maneira, amenizar ou mesmo reverter certos aspectos da 
interação entre universidade e escola no tocante à desvalorização do professor e a autoridade em sala de aula. Em primeiro lugar, Brasil ocupou incomodamente o primeiro lugar no ranking de desrespeito aos professores por parte dos alunos.(see Peter Dolton, 2018). Parece-nos que tais elementos foram objeto de reflexão/ação no caso da comunidade escolar em tela, o que demonstra que o projeto de Residência Pedagógica foi bem conduzido/delegado pelos coordenadores, acadêmicos, dirigentes escolares, alunos, professores e comunidades são positivas (Carnoy, 2009). Portanto, caberia às autoras, em outra oportunidade, avaliar o impato deste capital socio-familiar sobre os resultados do rendimento de professores e alunos atendidos pleo Programa Residência Pedagógica no município de Paranaguá. Com se porde constataro o "Residência Pedagógica" na UNESPAR (Paranaguá) é um sucesso, pois avalia-se o próprio fazer docente, o papel da escola, o processo de ensino aprendizagem, a motivação e a participação social dos alunos, projetos integradores, os benefícios ao corpo docente e discente de biologia, a comunidade escolar abrangida pelo programa. Deste modo, pelo teor, qualidade e consistência da argumentação, recomendamos sua imediata publicação do presente artigo.

\section{References}

Pierre Bourdieu. Les trois états du capital culturel. Actes de la Recherche en Sciences Sociales, n. 31, pp. 3-6., 1979.

BRASIL. MEC lança Política Nacional de Formação de Professores com Residência Pedagógica. Ministério da Educação, Disponível em http://portal.mec.gov.br/ultimas-noticias/211-218175739/55921-mec-lancapolitica-nacional-de-formacao-de-professores-com-80-mil-vagas-para-residencia-pedagogica-em-2018, 2018.

Martin Carnoy. A vantagem acadêmica de Cuba. Por que seus alunos vão melhor na escola. Fundação Lemann - Ediouro, 2009.

James S. Coleman. Social Capital in the Creation of Human Capital. American Journal of Sociology, v.94, pp. 95-120, 1988.

Robert de Vries Po-Wen She p. 47). Peter Dolton, Oscar Marcenaro. Global Teacher Status Index. Varkey Foundation, p. 47, 2018. 